Original Article (short paper)

\title{
Association of organized physical activity and levels of cardiorespiratory fitness with indicators of mental health in children
}

\author{
Camila Felin Fochesatto ${ }^{1}$ (D), Adroaldo Cezar Araujo Gaya ${ }^{1}$ (iD), Denise Ruschel Bandeira ${ }^{2}$ (D), Jorge Mota ${ }^{3}$ (D), \\ Roberto Farina de Alemeida $^{4}$ (iD, Arieli Fernandes Dias ${ }^{1}$ (iD, Caroline Brand ${ }^{1}$ iD , Júlio Brugnara Mello ${ }^{1}$ id , \\ Anelise Reis Gaya ${ }^{1}$ iD \\ ${ }^{1}$ Universidade Federal do Rio Grande do Sul, Escola de Educação Física, Fisioterapia e Dança, Programa de \\ Pós-Graduação em Ciências do Movimento Humano, Projeto Esporte Brasil, PROESP-Br, Porto Alegre, RS, \\ Brazil; ${ }^{2}$ Universidade Federal do Rio Grande do Sul, Grupo de Estudo, Aplicação e Pesquisa em Avaliação \\ Psicológica, Porto Alegre, RS, Brazil; ${ }^{3}$ Universidade do Porto, Faculdade de Esportes, Centro de Pesquisa em \\ Atividade Física, Saúde e Lazer, Porto, Portugal, ${ }^{4}$ Universidade Federal de Ouro Preto, Ouro Preto, MG, Brazil
}

\begin{abstract}
Aim: To verify the associations between organized physical activity out of school (PA) and cardiorespiratory fitness (CRF) with indicators of mental health in children. Methods: This is a cross-sectional study, with a sample of 226 students (47\% girls) of public school in the south of Brazil aged between 6 to 11 years-old $(8.36 \pm 1.46)$. The cardiorespiratory fitness was measured by running and walking-test in six minutes, following the procedures of the "Brazil Sports Project". PA was evaluated through a question and the Strengths and Difficulties Questionnaire assessed mental health indicators. Generalized linear regressions were used with a confidence interval of $95 \%$. Results: Total difficulties ( $\beta=2.691 ; 95 \% \mathrm{CI}, 0.181$ to 5.200$)$ and emotional symptoms ( $\beta=1.528 ; 95 \% \mathrm{CI}, 0.609$ to 2.448$)$ were inversely associated with PA. Total difficulties $(\beta=-0.013$; $95 \% \mathrm{CI},-0.022$ to -0.003$)$, hyperactivity/attention deficit ( $\beta=-0.002 ; 95 \% \mathrm{CI},-0.010$ to -0.002$)$, and peer relationship problems $(\beta=-0.002 ; 95 \% \mathrm{CI},-0.003$ to -0.001$)$ were associated with $\mathrm{CRF}$ in boys. Conclusion: A total of difficulties and emotional problems presented an inverse association with PA. Further, CRF was inversely associated with total difficulties, hyperactivity-inattention, and peer relationship problems.
\end{abstract}

Keywords: mental health; physical activity, cardiorespiratory fitness; school children.

\section{Introduction}

In children, mental health condition is based on age-appropriate emotional and social-cognitive development once those factors indicate the ability of adaption to challenging events ${ }^{1}$. On the other hand, mental disorders comprised a range of issues with distinct symptoms. Usually, they are characterized by an association of thoughts, emotions, behaviors, and relationships with others beyond the expected pattern ${ }^{2}$.In the world, it is estimated that around $13 \%$ of the children present some mental disorder ${ }^{3}$. In Brazil, these indicators are similar, showing a prevalence ranging from 10 to $20 \%{ }^{4}$. These disorders have been associated to genetic alterations, or to impacts resulting from environmental alterations such as extremely stressful situations, chronic adversities, loss of people that are close to the child, violence, besides sociocultural problems compromising the child development $^{5}$. The persistence of these stressful events increased the risk in social and personal inter-relationships, academic difficulties and low self-esteem, which are closely related to characteristic symptoms of several mental disorders and behaviors ${ }^{6}$.

Recently, regular physical activity (PA) practice has been recognized as an alternative to attenuate the symptoms related to mental and behavioral disorders ${ }^{7}$. Biddle, Asare ${ }^{8}$ suggested a small but positive effect of PA in young people's mental health indicators. Those studies showed that PA may lead to neurobiological, psychosocial and behavioral changes that most likely explain improvements in mood state and self-esteem? ${ }^{9}$.

In addition, it is well known that high levels of cardiorespiratory fitness (CRF) also act as a factor of attenuation and protection regarding the mental health indicators symptomatology. Such evidence are observed in the adult populations ${ }^{10}$ while a reduced number of studies aimed to elucidate the relationships between the different contexts of PA practice and the CRF levels with mental health in children $^{8}$ and fewer in the Brazilian population, which highlights the relevance of our study. In addition, the results could be useful for the development of health promotion public policies. Thus, this study aimed to identify the associations between the organized PA out of school and CRF with the different mental health indicators in children. 


\section{Methods}

\section{Study design}

This study used a cross-sectional analysis of longitudinal data from a study aiming to evaluate the effects of a soccer intervention program on mental health, cognition, metabolic syndrome and inflammatory markers outcomes in children. Thus, for this study only baseline data were considered. The sample comprised of 232 students (114 girls) aged from six to 11 years old, from a public school in southern Brazil. All children from the first to fifth grade were invited to participate. The parents of the children who accepted to participate signed the consent form and the children, the term of assent. The study was approved by the Ethics and Research Committee with human beings of the Federal University of Rio Grande do Sul (2.611.180).

The minimum number of subjects was calculated through the software $\mathrm{G}^{*}$ Power version 3.1. For the sample size calculation, a weak effect size $\left(\mathrm{f}^{2}=0.13\right)$, a statistical power of 0.80 , and alfa equal to 0.05 were adopted. Considering mental health indicators as dependent variables, in which the generalized linear regression models by sex were used, with four predictors, and an increase of approximately 5\% to cover possible losses and refusals, a total of 110 children of each gender was recruited.

\section{Instruments and collection procedures}

Assessments were carried-out between March and May 2017. Initially, the researcher went to the school to explain the study objectives to the school managers, who signed an agreement form. Then, data collections were scheduled. CRF evaluation, body mass, and height measurements were performed in the school by a team of trained researchers during physical education classes. For data collection regarding mental health, organized PA out of school and socioeconomic level, the parents attended a meeting in which they answered a questionnaire. For those who could not attend, an individual meeting at the school was scheduled via telephone.

\section{Cardiorespiratory fitness}

In order to assess cardiorespiratory fitness, children performed the running and walking-test in 6 minutes. This test was used in Brazilian children and adolescents as a predictor of oxygen uptake peak ${ }^{11}$ and is internationally validated ${ }^{12}$. The students were divided by small groups appropriate to the dimensions of the sports court (usually 10). The importance of maintaining a constant running pace was emphasized, avoiding walks and sprints. Students were oriented to run as long as possible. During the test, the passage of time of 3' and 5' was informed. Through a sign, at the end of the test, the students interrupted the test remaining in the place where they were, so the distance performed during the 6 minutes (in meters) could be recorded.

\section{Organized physical activity out of school}

Organized PA out of school was characterized as a structured PA practiced with some purpose out of school hours or during leisure time. It was included in the present study because the students from the first to the fifth year of public schools do not have physical education classes in their curriculum. It was also conducted in order to identify if the children are engaged in any physical activity or sports practice during leisure time.

PA out of school was assessed through an anamnesis directed to the parents, assessed PA out of school. The questionnaire had several questions about their children, including: "Is your son engaged in any organized physical activity out of school, such as soccer, gymnastics or volleyball classes, among others?" The answers options were "yes" and "no".

\section{Anthropometric evaluation}

Height was assessed in centimeters with one decimal scale through a tape fixed on the wall and extended from the bottom up, with the children maintained upright, with their feet and trunk against the wall. Body mass was measured through an anthropometric scale, with a precision of 500 grams and recorded in kilograms with the use of one decimal scale. The children should be barefoot, wearing light clothes, standing with their arms close to their bodies. Both assessments followed the PROESP-Br ${ }^{13}$ procedures. Thus, body mass index (BMI) was calculated, determined by dividing body mass $(\mathrm{kg})$ by height $(\mathrm{m})$ squared.

\section{Socioeconomic level}

It was assessed by an adaption of the questionnaire of the Brazilian Association of Research Companies (2015) ${ }^{14}$ considering the head of a household's education level and the number of certain items they have, and then they received a score according to the response. The sum of these scores allowed to know the social class in which the family is allocated: A1, A2, B1, B2, C1, $\mathrm{C} 2$, D or E. Then, the social classes were categorized as high $(\mathrm{A} 1+\mathrm{A} 2)$, middle $(\mathrm{B} 1+\mathrm{B} 2+\mathrm{C} 1+\mathrm{C} 2)$ and low $(\mathrm{D}+\mathrm{E})$.

\section{Mental health}

Mental Health was evaluated through the "Strengths and Difficulties Questionnaire" (SDQ) ${ }^{15}$, which consists of a behavioral screening of children. It presents three versions that could be answered by children, teachers, and, in this case, by the children's parents/guardians. SDQ approaches behavioral questions in children between 03 and 12 years old. It contains 25 items, which are organized into five domains: emotional symptoms, conduct problems, hyperactivity-inattention; peer relationship problems; and pro-social behavior. The responsible person should take into account the last six months of the children to mark "True", "More or less true" and "False".

For the final analysis, the scores were generated for the domains used in this study (emotional symptoms, conduct problems, hyperactivity-inattention; peer relationship problems), through the sum of these four indicators (total difficulties). Pro-social behavior was not included in the study as it is positive conduct. For all the above-mentioned domains, we used the cut-off points suggested by SDQ splitting the indicators as healthy and risk for health. Thus, a sum of the five questions in each domain was performed, and, for the total of difficulties, the sum of the four domains was performed. The score established 
by the questionnaire is: healthy (total difficulties: $0-16$; emotional symptoms: $0-4$; conduct problems: $0-3$; hyperactivityinattention: 0-6 peer relationship problems: $0-3$ ) and risk (total of difficulties: above 17; emotional symptoms: above 5; conduct problems: above 4, hyperactivity-inattention: above 7; peer relationship problems: above 4).

\section{Statistical analysis}

Descriptive data are shown as mean, standard deviation and frequency. All variables were tested for normality through the Shapiro-Wilk test. The variable that did not present a normal curve (conduct problems and peer relationship problems) were transformed into a square root. Differences between genders were analyzed through the independent $t$ test and the Pearson chi-square test.

In addition, the internal consistency of the SDQ scales was calculated using Cronbach's Alfa, indicating 0.80 (total of difficulty) as acceptable reliability. The results obtained for each domain were, respectively: 0.55 for emotional symptoms; 0.62 for conduct problems; 0.72 for hyperactivity-inattention; and 0.47 for peer relationship problems.

Generalized linear regression analyses to verify associations between variables of interest were used. For all analyses it was used the software IBM SPSS version 20.0, considering alfa of $5 \%$. The dependent variables of the present study were mental health indicators (total of difficulties, emotional symptoms, conduct problems, hyperactivity-inattention, and peer relationship problems) and the independent variables consisted of the organized PA out of school and CRF, stratified by sex. All analyses were adjusted by socio-economic level and age. The adjustment variables of the model were defined based on the existing literature. In addition, multicollinearity values were tested.

\section{Results}

Table 1 presents the characteristics of the sample. A difference between CRF means was found with boys having better performance than girls $(\mathrm{t}=3.39 ; \mathrm{p}=0.001 ; \mathrm{d}$ Cohen $=0.39)$.

Table 2 presents the associations between organized PA out of school and CRF with mental health indicators, adjusted for socioeconomic level and age. Boys who practice organized PA out of school score lower in total difficulties by 2,691 points and in emotional symptoms by 1,528 points compared to those who do not practice PA out of school. Regarding CRF indicators, an inverse association was also observed with the total of difficulties (-0.013), hyperactivity-inattention (-0.006) and peer relationship problems $(-0.002)$ in boys.

\section{Discussion}

Our results indicated an elevated number of children with the risk of developing different mental health indicators. Moreover, inverse associations were found between CRF levels and organized PA practice out of school with mental health indicators in boys.

Literature presents distinct values regarding the risk of mental health indicators in children. A similar study conducted with Brazilian children showed equivalent values to ours ${ }^{16}$. On the other hand, international studies presented lower prevalen$\operatorname{ces}^{3,17}$. These differences can be explained by each country par-

Table 1 - Descriptive characteristics of sample, separated by sex.

\begin{tabular}{|c|c|c|c|c|}
\hline \multirow[t]{2}{*}{ Characteristics of sample } & \multicolumn{2}{|c|}{ Boys $(n=118)$} & \multicolumn{2}{|c|}{ Girls $(n=114)$} \\
\hline & $\mathbf{N}$ & Mean (SD) & $\mathbf{N}$ & Mean (SD) \\
\hline Total difficulties (points) & 118 & $11.58(6.61)$ & 108 & $11.29(5.69)$ \\
\hline Emotional symptoms (points) & 118 & $3.47(2.32)$ & 108 & $3.19(2.10)$ \\
\hline Hyperactivity-inattention (points) & 118 & $4.19(2.72)$ & 108 & $4.20(2.39)$ \\
\hline Conduct problems (points) & 118 & $1.16(0.80)$ & 108 & $1.23(0.78)$ \\
\hline Peer relationship problems (points) & 118 & $1.11(0.83)$ & 108 & $1.12(0.71)$ \\
\hline $\mathrm{CRF}(\mathrm{m})$ & 102 & $791.37(138.07)^{\mathrm{a}}$ & 100 & $749.75(109.46)$ \\
\hline BMI $\left(\mathrm{kg} / \mathrm{m}^{2}\right)$ & 112 & $17.93(3.51)$ & 108 & $17.96(4.10)$ \\
\hline \multirow[t]{2}{*}{ Age (years) } & 118 & $8.42(1.45)$ & 107 & $8.44(1.53)$ \\
\hline & $\mathbf{N}$ & $\%$ & $\mathbf{N}$ & $\%$ \\
\hline \multicolumn{5}{|l|}{ PA } \\
\hline Yes & 57 & 49.6 & 41 & 39.0 \\
\hline No & 58 & 50.4 & 64 & 61.0 \\
\hline \multicolumn{5}{|l|}{ SES } \\
\hline Middle & 37 & 32.5 & 32 & 31.4 \\
\hline Low & 77 & 67.5 & 70 & 68.6 \\
\hline
\end{tabular}

CRF: Cardiorespiratory fitness; BMI: Body mass index; PA: physical activity; SES: socioeconomic status; N: number of subjects; SD: standard deviation; ${ }^{\mathrm{a}}$ statistically significant difference between boys and girls $\mathrm{p}<0,05$ for independent $\mathrm{T}$ test. 
Table 2 - Association of organized PA out of school and CRF with indicators of mental health.

\begin{tabular}{|c|c|c|c|c|c|c|}
\hline & \multicolumn{3}{|c|}{ Boys $(n=96)$} & \multicolumn{3}{|c|}{ Girls $(n=93)$} \\
\hline & $\beta$ & $95 \%$ CI & $\mathbf{p}$ & $\beta$ & $95 \%$ CI & $\mathbf{p}$ \\
\hline \multicolumn{7}{|c|}{ Total difficulties } \\
\hline \multicolumn{7}{|l|}{ PA } \\
\hline \multicolumn{7}{|l|}{$\mathrm{No}^{\mathrm{a}}$} \\
\hline Yes & -2.691 & $(-5.200$ to -0.181$)$ & $0.03 *$ & -1.845 & $(-4.040$ to 0.350$)$ & 0.09 \\
\hline CRF & -0.013 & $(-0.022$ to -0.003$)$ & $<0.01 *$ & -0.005 & $(-0.0151 .045)$ & 0.30 \\
\hline
\end{tabular}

\section{Emotional symptoms}

PA

\begin{tabular}{ccccccc} 
No $^{\mathrm{a}}$ & & & & & \\
Yes & -1.528 & $(-2.448$ to -0.609$)$ & $<0.001^{*}$ & -0.714 & $(-1.563$ to 0.135$)$ & 0.09 \\
CRF & -0.001 & $(-0.0050 .002)$ & 0.56 & -0.001 & $(-0.0050 .003)$ & 0.52 \\
\hline
\end{tabular}

\section{Hyperactivity-inattention}

\section{PA}

\begin{tabular}{ccccccc}
$\mathrm{No}^{\mathrm{a}}$ & & & & & \\
Yes & -0.425 & $(-1.500$ to 0.649$)$ & 0.43 & -0.771 & $(-1.749$ to 0.208$)$ & 0.12 \\
CRF & -0.006 & $(-0.010-0.002)$ & $<0.001 *$ & -0.001 & $(-0.0050 .004)$ & 0.73 \\
\hline
\end{tabular}

\section{Conduct problems}

PA

\begin{tabular}{ccccccc} 
No $^{\mathrm{a}}$ & 1 & & & & & \\
Yes & -0.242 & $(-0.554$ to 0.070$)$ & 0.12 & -0.010 & $(-0.321$ to 0.302$)$ & 0.95 \\
CRF & 0.000 & $(-0.0010 .001)$ & 0.84 & 0.000 & $(-0.0020 .001)$ & 0.53 \\
\hline
\end{tabular}

Peer relationship problems

\section{PA}

\begin{tabular}{ccccccc}
$\mathrm{No}^{\mathrm{a}}$ & 1 & & & & \\
Yes & -0.154 & $(-0.470$ to 0.163$)$ & 0.34 & -0.253 & $(-0.529$ to 0.023$)$ & 0.07 \\
CRF & -0.002 & $(-0.003-0.001)$ & $<0.001 *$ & 0.000 & $(-0.0020 .001)$ & 0.46 \\
\hline
\end{tabular}

${ }^{a}$ reference category; PA: organized PA out school CRF: cardiorespiratory fitness; 95\%CI: 95\% confidence interval lower and upper. All analyzes were adjusted for socioeconomic level and age. ${ }^{*} \mathrm{p}<0,05$.

ticularities, as economic and educational development levels as well as social issues that could compromise the estimated prevalence, when considering different places of the world.

In addition, the present study aimed to analyze the associations between different PA indicators with some mental health disorders already evidenced in children ${ }^{18-20}$. Among the different factors associated with mental health, the literature suggests the importance of regular PA practice, due to its social and behavioral roles, but also the relevance of neurobiological effects from exercise by means of changes in structural and functional compositions of the brain, which may be associated to the prevention and attenuation of mental disorders ${ }^{21}$.

Given that, the results of our study might provide an additional contribution to better understanding of the relationships between PA practice and the different mental health indicators in children. Indeed, our findings showed that the total of difficulties was associated with both PA regular practice out of school and CRF levels in boys. Such results are in accordance with the study of Khan, Hillman ${ }^{22}$ indicating that adolescents who did not reach daily $\mathrm{PA}$ recommendations $(<60 \mathrm{~min} /$ day $)$, presented greater scores of difficulties. In the same population, Sagatun, Søgaard, Bjertness, Selmer, Heyerdahl ${ }^{19}$ showed that those who practiced between 5 and 7 hours of PA per week were those who presented the lowest scores of total numbers of difficulties. Although limited, the studies investigating these relationships, reported similar results between 4 and 12 years old. ${ }^{20}$ It should be noted that such findings are more consistent in boys than girls. This may be associated with the increasingly significant reduction of girls involved in regular PA practices ${ }^{23}$.

Regarding the association between organized PA practice out of school and emotional symptoms, Ortlieb et al. ${ }^{18}$ found similar results and suggested that PA practice, independent of CRF levels, is associated with emotional symptoms indicators. However, this study carried-out with German girls who were 
followed over 10 years, and the opportunity of involvement in moderate PA was associated with lower scores of emotional symptoms. Moreover, a previous study conducted with boys using the same instrument of the present study showed that the number of hours spent in PA per week was inversely associated with emotional symptoms ${ }^{19}$. Therefore, the socialization with friends or colleagues that the PA promotes may contribute to the improvement of anxiety and depression symptoms, as contact with other children assists in mental well-being.

Another important aspect to be considered is that moderate/vigorous PA can contribute to the improvement of CRF, which is an important general health indicator of children ${ }^{24}$. Recent evidence showed that increased CRF levels are associated with improved mental health in adults ${ }^{9}$. Besides assisting in the improvement of mental health, elevated levels of CRF act as protectors of possible future depressive events, given that CRF is physiologically associated with the functional connectivity of the brain ${ }^{10}$. Thus, the present study adds new evidence on this topic in the child population. The results found show that the total of difficulties, hyperactivity-inattention, and peer relationship problems are negatively associated with CRF levels in boys. However, we did not find data in the literature corroborating the findings regarding the total of difficulties and hyperactivity-inattention.

Regarding peer relationship problems, Smith, UllrichFrench, Ii, Hurley ${ }^{25}$ showed that children with a better relationship with their peers felt more motivation to practice sports and, consequently, present better CRF levels. Despite the scarcity of studies in this topic, a hypothesis that could explain the relationship between mental health and CRF levels lies in the understanding that CRF would be directly associated with the inhibitory control, once better CRF levels are able to activate frontal and parietal circuits in more demanding cognitive tasks ${ }^{26}$. Thus, regular PA practice may promote better CRF levels and, consequently, can be related to changes in mental health indicators. For that, there are possible functional and physiological explanations. The first hypothesis explains that PA promotes improvements in attention and information processing. The second indicates the benefits of PA in increasing cerebral blood flow, neuroplasticity, neurotransmitter levels as serotonin and noradrenaline and the production of neurophins as the brainderived neurotrophic factor ${ }^{27}$. Moreover, PA and sports practice, independent of the improvement in physical fitness levels, promote the involvement in social relationships, which can also improve mental health.

This study brings new information regarding the relationship between mental health and PA, approaching different behavioral and emotional indicators. In addition, to the best of our knowledge, this is one of the first studies considering the association between CRF levels and mental health in Brazilian children. We emphasize the relevance of investigating this topic, considering that mental health problems have been appearing earlier and more frequently in life. Thus, regular PA practice could be considered a condition and behavior related to the prevention and treatment of these different disorders.

Despite the relevance of these findings, some limitations must be considered. This study has a cross-sectional design, which does not allow determining the cause-effect relationship. In addition, mental health and PA were indirectly measured. We also understand the risk of bias when parents report about PA and mental health of their children since once they do not spend all the time together. Even so, we consider that parents are the most suitable to answer about competence, behavior problems and the PA of their children. The sample was not representative, which does not allow extrapolating the data for the entire population. However, SDQ is a valid and adequate instrument for this type of research ${ }^{28}$. Besides, this study is one of the pioneers in children, it can be used as a basis for future epidemiological researches. In order to advance in this area, population and intervention studies are required in this context, as well as to consider the type, intensity and time spent in PA.

In conclusion, organized PA out of school and CRF levels are inversely associated with mental health indicators in boys. A total of difficulties and emotional problems presented an inverse association with PA. Moreover, CRF was inversely associated with total difficulties, hyperactivity-inattention, and peer relationship problems.

\section{References}

1. Estanislau GM, Bressan RA. Saúde mental na escola: o que os educadores devem saber. 2014. 277 p.

2. World Health Organization. Mental Health: Action Plan 20132016. World Health Organization, editor. Geneva; 2013.

3. Polanczyk G V, Salum GA, Sugaya LS, Caye A, Rohde LA. Annual Research Review: A meta-analysis of the worldwide prevalence of mental disorders in children and adolescents. 2015.

4. Ministério Da Saúde. Brasil. Secretaria de Atenção à Saúde. Departamento de Ações Programáticas e Estratégicas. Caminhos para uma Política de Saúde Mental Infanto-Juvenil. Brasília: Ministério da Saúde, 2005. v. 1. 76p. (Série B). Textos Básicos em Saúde.

5. Feitosa HN, Ricou M. A saúde mental das crianças e dos adolescentes: considerações epidemiológicas, assistenciais e bioéticas. Revista Bioética, 2011;19(1):259-76.

6. Hawgood J, De Leo D. Anxiety disorders and suicidal behaviour: an update. Curr Opin Psychiatry. 2008;21(1):51-64.

7. Radovic S, Gordon MS, Melvin GA. Should we recommend exercise to adolescents with depressive symptoms? A metaanalysis. J Paediatr Child Health. 2017;53(3):214-20.

8. Biddle SJH, Asare M. Physical activity and mental health in children and adolescents: a review of reviews. Br J Sports Med. 2011;45:886-895.

9. Stubbs B, Rosenbaum S, Vancampfort D, Ward PB, Schuch FB. Exercise improves cardiorespiratory fitness in people with depression: A meta-analysis of randomized control trials. J Affect Disord. Elsevier; 2016;190:249-53.

10. Schuch FB, Vancampfort D, Sui X, Rosenbaum S, Firth J, Richards J, et al. Are lower levels of cardiorespiratory fitness associated with incident depression A systematic review of prospective cohort studies. Prev Med (Baltim). Elsevier Inc.; 2016;93:15965.

11. Bergmann G, Bergmann M, Castro A, Lorenzi T, Pinheiro E, Moreira R, et al. Use of the 6-minute walk/run test to predict peak oxygen uptake in adolescents. Revista Brasileira de Atividade Física \& Saúde, v. 19, n. 1, p. 64-64, 2014. 
12. Granacher U, Borde, R. Effects of sport-specific training during the early stages of long-term athlete development on physical fitness, body composition, cognitive, and academic performances. Frontiers in physiology, v. 8, p. 810, 2017.

13. Gaya A, Lemos A, Gaya A, Teixeira D, Pinheiro E, Moreira R. PROESP-Br Projeto Esporte Brasil Manual de testes e avaliação. 2015;1-20.

14. Associação Brasileira de Empresas de Pesquisa ABEP. Critério de Classificação Econômica Brasil - CCEB. Códigos e guias. 2015;1-6.

15. Strengths \& Difficulties Questionnaires. Disponível em: https://sdqinfo.org/

16. Camargo Vitolo YL, Fleitlich-Bilyk B, Goodman R, Bordin IAS Crenças e atitudes educativas dos pais e problemas de saúde mental em escolares. Rev Saude Publica. 2005;39(5):716-24.

17. Cao H, Yan S, Gu C, Wang S, Ni L, Tao H, et al. Prevalence of attention-deficit / hyperactivity disorder symptoms and their associations with sleep schedules and sleep-related problems among preschoolers in mainland China. BMC Pediatrics; 2018;1-8.

18. Ortlieb S, Schneider G, Koletzko S, Berdel D, von Berg A, Bauer $\mathrm{C}-\mathrm{P}$, et al. Physical activity and its correlates in children: a cross-sectional study (the GINIplus \&amp; LISAplus studies). BMC Public Health. 2013;13(1):349.

19. Sagatun A, Søgaard AJ, Bjertness E, Selmer R, Heyerdahl S. The association between weekly hours of physical activity and mental health: A three-year follow-up study of 15-16-year-old students in the city of Oslo, Norway. BMC Public Health. 2007;7:1-9.

20. Griffiths LJ, Dowda M, Dezateux C, Pate R. Associations between sport and screen-entertainment with mental health problems in 5-year-old children. Int J Behav Nutr Phys Act. 2010;7.

21. Lubans D, Richards J, Hillman C, Faulkner G, Beauchamp M. Physical Activity for Cognitive and Mental Health in Youth?: A Systematic Review of Mechanisms. 2016;138(3).

22. Khan NA, Hillman CH. The Relation of Childhood Physical Activity and Aerobic Fitness to Brain Function and Cognition: A Review. Pediatr Exerc Sci. 2014;26(2):138-46.

23. Deng WH, Fredriksen PM. Objectively assessed moderate-tovigorous physical activity levels among primary school children in Norway: The Health Oriented Pedagogical Project (HOPP). Scand J Public Health. 2018;46(21_suppl):38-47.

24. Klakk H, Grontved A, Moller NC, Heidemann M, Andersen LB, Wedderkopp N. Prospective association of adiposity and cardiorespiratory fitness with cardiovascular risk factors in healthy children. Scand J Med Sci Sports. 2014;24(4):E275-82.
25. Smith AL, Ullrich-French S, Ii EW, Hurley KS. Peer Relationship Profiles and Motivation in Youth Sport. J Sport Exerc Psychol. 2006;28:362-82.

26. Haapala EA. Cardiorespiratory Fitness and Motor Skills in Relation to Cognition and Academic Performance in Children - A Review. J Hum Kinet. 2013 Mar;36:55-68.

27. Puhan MA, Chandra D, Mosenifar Z, Ries A, Make B, Hansel NN, et al. A Randomized Trial Examining the Effects of Aerobic Physical Activity on Attention-Deficit/Hyperactivity Disorder Symptoms in Young Children Betsy. J Abnorm Child Psychology. 2017;37(4):784-90.

28. Saur AM, Loureiro SR. Qualidades psicométricas do Questionário de Capacidades e Dificuldades: revisão da literatura. Estud Psicol. 2012;29(4):619-29.

\section{Acknowledgement}

National Council for Scientific and Technological Development, process number 401969/2016-9/ Universal Announcement. Foundation for Science and Technology (FCT), Portugal: SFRH/BSAB/142983/2018 and UID/DTP/00617/2019. Santander University Scholarship Program 2018. National Council for Scientific and Technological Development, process number 401969/2016-9/ Universal Announcement. Coordination of Superior Level Staff Improvement.

\section{Corresponding author}

Camila Felin Fochesatto

Escola de Educação Física.

Universidade Federal do Rio Grande do Sul.

Rua Felizardo, 750. Jardim Botânico. CEP 90690-200.

Porto Alegre, RS, Brazil.

E-mail: camila-fochesatto@hotmail.com

Manuscript received on April 16, 2019

Manuscript accepted on September 24, 2019

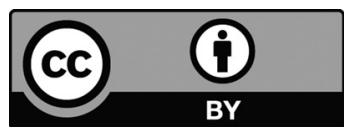

Motriz. The Journal of Physical Education. UNESP. Rio Claro, SP, Brazil eISSN: 1980-6574 - under a license Creative Commons - Version 4.0 